\title{
Bone mineral density in women on long-term mud-bath therapy in a Salus per Aquam (SPA) environment
}

\author{
A. Loi, S. Lisci, A. Denotti, A. Cauli \\ Centro Studi Antiche Terme di Sardara, Santa Maria de is Acquas, Sardara (CA), Italy
}

\begin{abstract}
SUMMARY
The objective of this study was to assess bone mineral density (BMD) in women on long-term mud-bath therapy (MBT) for osteoarthritis in a Salus per Aquam (SPA) environment.

Two hundred and fifty female patients were randomly enrolled in this study in the SPA center of Sardara (Cagliari, Italy) where they were treated with a combination of daily full body mudpacks and bicarbonate-alkaline mineral water baths at cycles of 2 weeks/year. BMD was evaluated by means of calcaneus ultrasonometry (Sahara Hologic Inc., Bedford, MA, USA) and results analyzed according to duration of treatment and clinical variables.

In the group of patients undergoing MBT for more than 10 years (group A) and for 3 to 10 years (group B) a reduced frequency of osteopenia and osteoporosis was detected (35.8\% and $7.6 \%$ group $\mathrm{A} ; 38.4 \%$ and $8.5 \%$ group B, respectively) compared to controls (group C) $(48.9 \%$ and $23.4 \%, \mathrm{P}<0.01$ and $\mathrm{P}<0.001)$. Furthermore, higher T-score values were detected in group A and B $(-1.05 \pm 1.28$ and $-1.24 \pm 0.94$, respectively) compared to group $\mathrm{C}(-1.93 \pm 0.78)(\mathrm{P}<0.0002$ and $\mathrm{P}<0.0001)$. Similar results were observed in the analysis of data restricted to women in menopause only.

Long-term mud-bath therapy in SPA environment appeared to be beneficial for BMD.
\end{abstract}

Key words: Mud-bath therapy, Osteoporosis, Osteoarthritis.

Reumatismo, 2013; 65 (3): 121-125

\section{INTRODUCTION}

$\mathrm{M}$ ud-bath therapy (MBT) represent a popular treatment for several rheumatic degenerative diseases, such as osteoarthritis, because of beneficial effects on the inflammatory pathway and bone metabolism which have been recently summarized by Fioravanti and colleagues $(1,2)$. Several studies have demonstrated MBT clinical efficacy in treating osteoarthritis in several joint sites (3-5), furthermore additional beneficial effects have been reported in patients with ankylosing spondylitis treated with anti-TNF alpha drugs (6), as well as in spondyloarthritis patients with chronic inflammatory bowel disease (7).

Osteoarthritis represents the most frequent chronic disease in the general population, with high prevalence in women after fifty years of age (24.4\%, ISTAT, www.salute. gov.it). Because osteoporosis affects main- ly women in the second part of their life, it has been questioned if MBT for osteoarthritis would be appropriate in this cohort of female patients. In the past it has been speculated that the heat stimulus could interfere with bone metabolism inducing an increase in bone loss, in this case MBT would have been considered not appropriate in osteoporotic subjects.

Osteoporosis is a disease characterized by a complex and multifactorial pathogenesis, a decrease in bone mineral density and by an alteration in the microstructure of bone, which causes an increase in bone fragility and risk of fracture (8). Osteoporosis is therefore a major health problem with a consistent and increasing social and economic impact. 'The Epidemiological Study on the Prevalence of Osteoporosis (ESOPO) (9) has been the first epidemiologic study on osteoporosis involving whole Italy. This study has revealed a prevalence $\overline{\text { Corresponding author: }}$ Dott. Antonello Loi Centro Studi di Medicina Termale Antiche Terme di Sardara Santa Maria Is'Acquas 09030 Sardara (Cagliari), Italy E-mail: antonello.loi@termedisardara.it 
of osteoporosis in $18.5 \%$ and osteopenia in $44.7 \%$ of women included in the $40-70$ years of age and in $10 \%$ and $36 \%$ in the male population in the 60-79 years of age. The importance of these data is linked to the increased risk of bone fracture (10, 11). Bone mineral density (BMD), measured in $\mathrm{g} / \mathrm{cm}^{2}$, is considered the most useful diagnostic tool and is assessed by means of dual emission x-ray absorptiometry (DEXA), which represent the gold standard for the diagnosis of osteoporosis, and by means of ultrasonometry (12). This last non-invasive technique present several features to be considered an ideal tool for screening BMD measurement in a thermal environment: absence of radiation, no need of dedicated rooms, easy to be transported, low cost. Several studies performed on healthy and on osteoporotic women, have demonstrated that the ultrasonic technique is able to separate the two populations of women and also to predict the risk of fractures, similarly to DEXA $(13,14)$.

On this basis, the aim of this study was to evaluate BMD in a large cohort of women with osteoarthritis attending a Salus per Aquam (SPA) resort for MBT, and to analyze the results according to different clinical variables.

\section{MATERIALS AND METHODS}

A cohort of 250 female patients with osteoarthritis, attending the SPA resort Antiche Terme di Sardara (Sardegna, Italy) clinic for MBT, have been randomly recruited over three years for this study. All patients were Caucasian, resident in the nearby area of the SPA resort.

The patients were treated daily with a combination of full body mud packs applied for $20 \mathrm{~min}$ at an initial temperature of $45^{\circ} \mathrm{C}$ followed by bicarbonate-alkaline mineral water (Tab. I) bath at $38^{\circ} \mathrm{C}$ for 10 $\mathrm{min}$, and by $45 \mathrm{~min}$ of rest, for a total of 12 applications carried out over a period of 2 weeks. Physical therapy schemes were not included in the protocol. Patients have been recruited randomly following referral from general practitioner to have MBT
Table I - Chemical and physical characteristics of Sardara thermal water employed in mud-bath therapy, according to Marotta and Sica: sodium bicarbonate alkaline water $\left(56.4^{\circ} \mathrm{C}\right)$.

\begin{tabular}{|l|l|}
\hline Bicarbonates & $26.0 \mathrm{meq} / \mathrm{L}$ \\
Calcium & $27.0 \mathrm{mg} / \mathrm{L}$ \\
Chlorides & $530.0 \mathrm{mg} / \mathrm{L}$ \\
Iron & $0.30 \mathrm{mg} / \mathrm{L}$ \\
Fluorides & $10.1 \mathrm{mg} / \mathrm{L}$ \\
Magnesium & $6.6 \mathrm{mg} / \mathrm{L}$ \\
Nitrates & $1.4 \mathrm{mg} / \mathrm{L}$ \\
Nitrites & $0.020 \mathrm{mg} / \mathrm{L}$ \\
Potassium & $41.0 \mathrm{mg} / \mathrm{L}$ \\
Silica & $55.6 \mathrm{mg} / \mathrm{L}$ \\
Sodium & $1220.0 \mathrm{mg} / \mathrm{L}$ \\
Solphate & $56.0 \mathrm{mg} / \mathrm{L}$ \\
Phosphates & $0.0 \mathrm{mg} / \mathrm{L}$ \\
Free carbon dioxide & $115.0 \mathrm{mg} / \mathrm{L}$ \\
Electrical conductivity (at $\left.20^{\circ} \mathrm{C}\right)$ & $3380 \mathrm{micrS} / \mathrm{cm}$ \\
Oxidizability & $0.8 \mathrm{mgO} / \mathrm{L}$ \\
PH & $7.4 \mathrm{adimens}$ \\
Fixed residue (at $\left.180^{\circ}\right)$ & $2425 \mathrm{mg} / \mathrm{L}$ \\
\hline
\end{tabular}

for osteoarthritis, according to the National Health Service guidelines. Patients with co-pathologies which may cause osteopenia have been excluded, as well as patients on drugs which interfere with bone metabolism (Tab. II). All patients have participated in the study on voluntary basis, providing informed consent, according to good clinical practice.

During their stay in the SPA center all recruited patients underwent BMD evaluation by means of calcaneus ultrasonometry (Sahara Hologic Inc., Bedford, MA, USA) according to two parameters: T-score, number of standard deviation compared to the mean observed in young healthy subjects; Z-score, number of standard deviation compared to the mean in healthy subjects of the same age.

The following clinical variables have been recorded: age, weight, height, age of menopause onset, number of pregnancies, previous fractures, therapy for osteopenia/osteoporosis, years of MBT. The BMD results have been analyzed according to:

1) years of MBT: 10 or more years, group $\mathrm{A}$; three to nine years, group $\mathrm{B}$; never treated with MBT or maximum two occasional treatments in their life, group C (control group);

2) onset of menopause: Yes or No. 
Table II - Clinical characteristics of the patients included in the study and inclusion/exclusion criteria.

\begin{tabular}{|l|l|}
\hline Patients & 250 \\
\hline Sex & 250 female/0 male \\
\hline Mean age & $63.3 \pm 10.5$ \\
\hline BMI & $25.8 \pm 4.3$ \\
\hline Inclusion criteria & MBT for osteoarthritis \\
\hline Exclusion criteria: & $\begin{array}{l}\text { Joint swelling or effusion, } \\
\text { arthroprosthesis carrier, } \\
\text { cardiovascular or neurologic } \\
\text { severe diseases, peripheral } \\
\text { vascular diseases, neoplasm, } \\
\text { every other conditions that, } \\
\text { according to physician } \\
\text { would contraindicate MBT or } \\
\text { participation to the study. }\end{array}$ \\
\hline $\begin{array}{l}\text { Pharmacological } \\
\text { therapy }\end{array}$ & $\begin{array}{l}\text { On therapy with: } \\
\text { bisphosphonates, HRT, } \\
\text { SERMS, calcium and vitamin } \\
\text { D supplements, parathyroid } \\
\text { hormone-related peptides, } \\
\text { anticoagulants, every other } \\
\text { pharmacological treatment } \\
\text { that, according to physician, } \\
\text { would contraindicate MBT or } \\
\text { participation to the study. }\end{array}$ \\
\hline
\end{tabular}

BMI, body mass index; MBT, mud-bath therapy; HRT, hormone replacement therapy; SERMS, selective estrogen receptor modulators.

BMD data have been expressed in T- and $\mathrm{Z}$-scores and have been analyzed in relation to the clinical variables and according to time of MBT, values were expressed as mean \pm SD. Statistical analysis has been performed with Statistica 6.0 (StatSoft Inc., Tulsa, OK, USA) according to Chi-square test and T student test. P values less than 0.05 were considered statistically significant.

\section{RESULTS}

Analysis of T-score values in relation to time of MBT has revealed in groups A and $\mathrm{B}$ a minor frequency of osteopenia and osteoporosis, compared to control group $\mathrm{C}$, in details: in group A (MBT >10 years) BMD values indicating osteopenia were detected in $35.8 \%$ and osteoporosis in $7.6 \%$, in group B (MBT 3-10 years) BMD values indicating osteopenia were detected in $38.4 \%$ and osteoporosis in 8.5\%, compared to control group C (48.9\% and $23.4 \%$ respectively, $\mathrm{P}<0.01$ and $\mathrm{P}<0.001)$.

Table III shows T- and Z-scores in the studied groups. In summary, whole cohort analysis (Tab. III, upper grid) shows statistical differences in group A (T-score - $1.05 \pm 1.28$ $\mathrm{SD}$ ) and $\mathrm{B}$ (T-score $-1.24 \pm 0.94 \mathrm{SD}$ ), characterized by long term MBT, compared to control group C (T-score $-1.93 \pm 0.78 \mathrm{SD}$ ). Z-score values analysis also showed statistical differences between group $\mathrm{A}$ and $\mathrm{B}$ compared to control group $\mathrm{C}(\mathrm{P}<0.0001)$. Similar results were found when only women in menopause were included in the analysis, mean values of T-score and Z-score showed higher values of BMD in group A and B compared to control group C (Tab. III, lower grid).-

\section{DISCUSSION}

The results emerging from this study, although the limitations due to a crosssectional study, allow to draw several ob-

Table III - Mean values $\pm S D$ of T-score and Z-score in whole cohort of patients and restricted to women in menopause only. Patients have been stratified in sub-groups according to time of mud-bath therapy (MBT): group A, 10 or more years of MBT; group B, 3-9 years of MBT; group $C$, never or maximum two occasional MBT cycles in life.

\begin{tabular}{|c|c|c|c|c|}
\hline & T-score & $P$ value & Z-score & $P$ value \\
\hline \multicolumn{5}{|l|}{ Whole cohort } \\
\hline $\mathrm{A}(>9$ years of MBT) no. 39 & $-1.05 \pm 1.28$ & $=0.0002$ & $0.33 \pm 1.18$ & $<0.0001$ \\
\hline$B(3-9$ years of MBT) no. 164 & $-1.24 \pm 0.94$ & $<0.0001$ & $-0.46 \pm 0.87$ & $<0.0001$ \\
\hline C (controls) no. 47 & $-1.93 \pm 0.78$ & - & $-1.24 \pm 0.84$ & - \\
\hline \multicolumn{5}{|l|}{ Patients in menopause only } \\
\hline $\mathrm{A}(>9$ years of MBT) no. 36 & $-1.25 \pm 1.18$ & $<0.0001$ & $-0.10 \pm 1.01$ & $<0.0001$ \\
\hline$B(3-9$ years of MBT) no. 153 & $-1.38 \pm 0.94$ & $<0.0001$ & $-0.57 \pm 0.89$ & $<0.0001$ \\
\hline C (controls) no. 39 & $-2.05 \pm 0.80$ & - & $-1.30 \pm 0.95$ & - \\
\hline
\end{tabular}

MBT, mud-bath therapy. 
servations on the extent of osteopenia/osteoporosis in a cohort of women on MBT in SPA environment.

- Rheumatic conditions which may benefit from thermal treatments, such as osteoarthritis, induce patients to start MBT after their forties, and this appear to be beneficial in terms of BMD (minor detection of osteopenia and osteoporosis, and statistical higher values of T-score and Z-score in group A and B, which regularly attended SPA clinics, compared to control group C).

- In patients in stable menopause, a minor frequency of osteopenia or osteoporosis and statistical higher values of T-score and Z-score were observed in subjects, which regularly attended SPA clinics (MBT) compared to controls.

Osteoporotic disease and SPA treatments can be approached in two ways: thermal treatments for osteoporosis or thermal treatments in patients with osteoporosis. Thermal treatments of osteoporosis may include calcium intake by means of mineral water (15) (for example in subjects with milk intolerance) in order to reach calcium daily need.

Furthermore, it has been demonstrated that regular MBT does not increase bone loss processes, and that previous concerns were not confirmed. Several studies, performed in SPA thermal clinics in patients with osteoarthritis, have evidenced the protective effect of MBT on cartilage and bone by means of a significant reduction in serum levels of IL-1 e TNF- $\alpha$ (16, 17), PGE2 and LTB4 (16), cytokines involved in osteoclast recruitment and in mechanisms of bone reabsorption and inflammatory joint pathways (2). Furthermore, a study performed on 40 female patients has showed an increase in serum levels of osteoblast function biomarkers after MBT, such as osteocalcin (bone GLA protein, BGP), produced only by osteoblasts, and bone alkaline phosphatase, considered to be a marker of new bone formation $(18,19)$.

On the basis of clinical and biological evidence we can therefore conclude that MBT not only is appropriate in patients with reduced BMD, but MBT may be considered as a complementary approach to drug treatment in patients with osteoporosis.

Osteoporosis affect a considerable part of the Italian population after their fifty years of age, it is therefore important a primary prevention of the disease which should start since young age by means of healthy life-style, calcium and vitamin D rich diet, avoiding smoke and high alcohol intake, regular physical exercise.

On this regard, in the interpretation of the results of this study showing a beneficial effect of MBT in BMD, we could not exclude the contribution of a further component: the subjects that have regularly attended the SPA clinics for MBT during several years may be more compliant patients, they could be more prone to follow an healthy life style that may reduce itself the occurrence of bone loss. On this regard we underline that the attitude of the patients to practice physical exercise has not been investigated.

In summary the data emerging from this study, although with the limitations derived from a cross-sectional study, suggests that MBT not only is appropriate in women with reduced $\mathrm{BMD}$, but it may contribute, probably by means of different mechanisms, to contrast the processes leading to bone loss.

\section{REFERENCES}

1. Fioravanti A, Cantarini L, Guidelli GM, Galeazzi M. Mechanisms of action of spa therapies in rheumatic diseases: What scientific evidence is there? Rheumatol Int. 2011; 31: 1-8.

2. Cozzi F, Carrara M, Sfriso P, et al. Anti-inflammatory effect of mud-bath applications on adjuvant arthritis in rats. Clin Exp Rheumatol. 2004; 22: 763-6.

3. Fioravanti A, Iacoponi F, Bellisai B, et al. Short- and long-term effects of spa therapy in knee osteoarthritis. Am J Phys Med Rehab. 2010; 89: 125-32.

4. Fioravanti A, Tenti S, Giannitti C, et al. Shortand long-term effects of mud-bath treatment on hand osteoarthritis: a randomized clinical trial. Int J Biometeorol. 2013; 57: 1-8.

5. Fioravanti A, Giannitti C, Bellisai B, et al. Efficacy of balneotherapy on pain, function and quality of life in patients with osteoarthritis of the knee. Int J Biometeorol. 2012; 56: 583-90. 
6. Ciprian L, Lo Nigro A, Rizzo M, et al. The effects of combined spa therapy and rehabilitation on patients with ankylosing spondylitis being treated with TNF inhibitors. Rheumatol Int. 2013; 33: 241-5.

7. Cozzi F, Podswiadek M, Cardinale G, et al. Mud-bath treatment in spondylitis associated with inflammatory bowel disease - a pilot randomised clinical trial. Joint Bone Spine. 2007; 74: 436-9.

8. Adami S, Bertoldo F, Brandi ML, et al. Società Italiana dell'Osteoporosi, del Metabolismo Minerale e delle Malattie dello Scheletro. Guidelines for the diagnosis, prevention and treatment of osteoporosis. Reumatismo. 2009; 61: 260-84.

9. Maggi S, Noale M, Giannini S, et al. ESOPO Study Group. Quantitative heel ultrasound in a population-based study in Italy and its relationship with fracture history: the ESOPO study. Osteoporos Int. 2006; 17: 237-44.

10. Lapi F, Simonetti M, Michieli R, et al. Assessing 5-year incidence rates and determinants of osteoporotic fractures in primary care. Bone. 2012; 50: 85-90.

11. Adami S, Bianchi G, Brandi ML, et al. Validation and further development of the WHO 10-year fracture risk assessment tool in Italian postmenopausal women: project rationale and description. Clin Exp Rheumatol. 2010; 28: 561-70.
12. Frediani B. La densitometria ossea: interpretazione clinica e valore diagnostico. Progressi in Reumatologia. 2000; 1: 32-46.

13. Frediani B, Acciai C, Falsetti P, et al. Calcaneus ultrasonometry and dual-energy X-ray absorptiometry for the evaluation of vertebral fracture risk. Calcif Tissue Int. 2006; 79: 223-9.

14. Gonnelli S, Cepollaro C, Agnusdei D, et al. Diagnostic value of ultrasound analysis and bone densitometry as predictors of vertebral deformity in postmenopausal women. Osteoporosis Int. 1995; 10: 353-8.

15. Meunier PJ, Jenvrin C, Munoz F, et al. Consumption of a high calcium mineral water lowers biochemical indices of bone remodeling in postmenopausal women with low calcium intake. Osteoporos Int. 2005; 16: 1203-9.

16. Bellometti S, Giannini S, Sartori L, Crepaldi G. Cytokine levels in osteoarthrosis patients undergoing mud bath therapy. Int J Clin Pharmacol Res. 1997; 17: 149-53.

17. Cohen-Solal M, de Vernejoul MC. Cytokines and osteoporosis. Rev Rheum. 1996; 63: 83-6.

18. Bellometti S, Galzigna L. Serum levels of a prostaglandin and a leukotriene after thermal mud pack therapy. J Investig Med. 1998; 46: 140-5.

19. Bellometti S, Berte F, Richelmi P, et al. Bone remodelling in osteoarthrosis subjects undergoing a physical exercise program. Clin Chim Acta. 2002; 325: 97-104. 